\title{
DIÁLOGOS ENTRE ARQUITETURA E FENOMENOLOGIA: DO MODERNO AO PÓS-MODERNO
}

\section{CONEXIONES ENTRE ARQUITECTURA Y FENOMENOLOGÍA: DE LO MODERNO A LO POSMODERNO}

\author{
CONNECTIONS BETWEEN ARCHITECTURE AND PHENOMENOLOGY: FROM MODERN TO \\ POSTMODERN
}

\section{VIZIOLI, SIMONE HELENA TANOUE}

Professora Doutora do Instituto de Arquitetura e Urbanismo da Universidade de São Paulo (IAU USP). E-mail: simonehtv@usp.br

\section{TIBERTI, MATEUS SEGNINI}

Mestrando em Arquitetura e Urbanismo pelo Instituto de Arquitetura e Urbanismo da Universidade de São Paulo (IAU USP). E-mail: mateus.tiberti@gmail.com

\section{BOTASSO, GABRIEL BRAULIO}

Doutorando em Arquitetura e Urbanismo pelo Instituto de Arquitetura e Urbanismo da Universidade de São Paulo (IAU USP). E-mail: gabriel.botasso@usp.br

\section{RESUMO}

Longe de ser um campo fechado em si mesmo, a Arquitetura sempre procurou estabelecer pontes com outros campos disciplinares - notadamente, com a Filosofia. Entre as correntes de pensamento que fomentaram e que continuam a instigar o pensamento arquitetônico está a fenomenologia. Tal corrente filosófica, fundada por Edmund Husserl no início do século XX, teve um papel fundamental nas discussões sobre a experiência, a relação corpo-espaço em projetos de Arquitetura, contribuindo para a formação e o desenvolvimento do pensamento arquitetônico Pós-Moderno - uma questão ainda pouco estudada e fonte de calorosos debates. É possível observar a influência da fenomenologia tanto nas questões de Teoria e História da Arquitetura, quanto nas discussões projetuais - em ambos, o problema do "empobrecimento" da experiência comparece de diversos modos. O presente artigo procura estabelecer diálogos entre o pensamento de três arquitetos e autores que têm a fenomenologia como base de suas discussões: o espanhol Jorge Otero-Pailos (1971-), o norueguês Christian Norberg-Schulz (1926-2000) e o finlandês Juhani Pallasmaa (1936-). Com a escolha destes autores, nota-se a persistência das discussões sobre a fenomenologia no interior do campo arquitetônico ao longo das décadas de 1970, 1990 e 2010, especialmente, nos contextos estadunidense e europeu. Além disso, observa-se que a fenomenologia arquitetônica não é um pensamento unívoco: ocorreram desenvolvimentos e modificações ao longo dos mais de 50 anos de discussões no meio acadêmico e no campo da prática profissional.

PALAVRAS-CHAVE: arquitetura pós-moderna; fenomenologia arquitetônica; experiência corporal; relação corpo-espaço; percepção.

\section{RESUMEN}

Lejos de ser un campo cerrado en sí mismo, la Arquitectura siempre ha buscado establecer puentes con otros campos disciplinarios - especialmente, la Filosofía. Entre las corrientes de pensamiento que han fomentado y siguen instigando el pensamiento arquitectónico está la fenomenología. Esta corriente filosófica, fundada por Edmund Husserl a principios del siglo XX, ha desempeñado un papel fundamental en los debates sobre la experiencia, la relación cuerpo-espacio en los proyectos arquitectónicos, contribuyendo a la formación y el desarrollo del pensamiento arquitectónico posmoderno, cuestión aún poco estudiada y fuente de cálidos debates. Es posible observar la influencia de la fenomenología tanto en cuestiones de Teoría e Historia de la Arquitectura, como en discusiones proyectuales - en ambas, el problema del "empobrecimiento" de la experiencia aparece de diferentes maneras. Este artículo busca establecer diálogos entre el pensamiento de tres arquitectos y autores que tienen la fenomenología como base de sus discusiones: el español Jorge Otero-Pailos (1971-), el noruego Christian Norberg-Schulz (19262000) y el finlandés Juhani Pallasmaa (1936-). Con la elección de estos autores, observamos la persistencia de los debates sobre la fenomenología en el campo de la Arquitectura a lo largo de los años 70, 90 y 2010, especialmente en los contextos estadounidense y europeo. Además, se observa que la fenomenología arquitectónica no es una vía de sentido único: se han producido avances y cambios a lo largo de más de 50 años de debates en el mundo académico y en la práctica profesional.

PALABRAS CLAVES: arquitectura posmoderna; fenomenología arquitectónica; experiencia cuerporal; relación cuerpo-espacio; percepción.

\section{ABSTRACT}

Far from being a closed field, Architecture has always sought to establish bridges with other disciplinary fields - specially, with Philosophy. Phenomenology is among the currents of thought that fostered and that continue to instigate the architectural thinking. This philosophical movement, founded by Edmund Husserl at the beginning of the 20th century, played a fundamental role in discussions about experience, the body-space relationship in architectural designs, helping the formation and development of the Post-Modern architectural thinking - a barely studied issue and source of heated debates. It is possible to observe the influence of 
phenomenology both in the questions of Theory and History of Architecture, as well as Design discussions - in both, the problem of the "impoverishment" of experience appears in several ways. This paper wants to establish dialogues between the thinking of three architects and authors who have phenomenology as the basis of their discussions: the Spanish Jorge Otero-Pailos (1971-), the Norwegian Christian Norberg-Schulz (1926-2000) and the Finnish Juhani Pallasmaa (1936-). With the choice of these authors, it is possible to note the persistence of discussions about phenomenology within the architectural field throughout the 1970s, 1990s and 2010s, especially in the American and European contexts. In addition, it is observed that architectural phenomenology is not a univocal thought: there were developments and modifications throughout the 50 years of discussions in the academic and practical fields.

KEYWORDS: postmodern architecture; architectural phenomenology; bodily experience; body-space relationship; perception.

Recebido em: 20/11/2020 Aceito em: 15/06/2021

\section{INTRODUÇÃO}

Questões envolvendo a experiência, a percepção, os sentidos, o corpo, o senso de identidade fazem parte do vocabulário de estudos no campo da Arquitetura e do Urbanismo, sobretudo nos debates iniciados no período pós-Segunda Guerra Mundial. Embora seja uma discussão com mais de seis décadas, é notável a atualidade desta problemática, manifestando-se tanto no campo acadêmico, quanto no trabalho prático dos arquitetos. Muitos são os estudiosos que se debruçam, atualmente, sobre o tema e, ao comparar as diversas investigações sobre o papel das questões perceptivas no campo da Arquitetura e do Urbanismo, notam-se distintas abordagens realizadas pelos autores que tratam desta temática.

Uma das trilhas é percorrida pelos arquitetos que elaboram, acima de tudo, uma crítica à Arquitetura denominada "espetacular", puramente visual e sem profundidade; entre eles, destaca-se o arquiteto finlandês Juhani Pallasmaa (1936-), para o qual haveria, na contemporaneidade, a ascensão de uma Arquitetura incapaz de proporcionar uma "experiência fenomenologicamente autêntica", conforme o autor. Seus ensaios são provocações que estimulam os leitores a pensar sobre as questões da percepção humana, especialmente no que se refere à hegemonia do sentido da visão.

Nesta seara, outros estudiosos, igualmente preocupados com a abordagem da percepção, pautam seus discursos no contexto histórico, como é o caso do arquiteto e historiador méxico-canadense Alberto PérezGómez (1949-) e Jorge Otero-Pailos (1971-), arquiteto e teórico espanhol. Ambos procuram sistematizar o modo como a percepção e a fenomenologia foram estudadas e incorporadas pelo campo da Arquitetura e do Urbanismo.

Christian Norberg-Schulz (1926-2000), arquiteto e historiador norueguês, traz o foco das questões fenomenológicas no campo da Arquitetura e do Urbanismo para o lugar. Norberg-Schulz apresenta novas ferramentas para a história da Arquitetura: indo além das fontes documentais tradicionais (como desenhos, plantas ou textos), o autor considerava a experiência das obras em si como uma fonte de informação para a elaboração da história da Arquitetura, criando uma narrativa também por meio de fotografias - seria um "fotohistoriador", consoante Otero-Pailos (2010).

Nesse cenário, o presente texto pretende debruçar-se sobre o estudo de olhares fenomenológicos no campo da Arquitetura e do Urbanismo a partir das perspectivas de Jorge Otero-Pailos (1971-), Christian Norberg-Schulz (1926-2000) e Juhani Pallasmaa (1936-), referentes ao período pós-Segunda Guerra Mundial. A escolha de tais autores tem como base os estudos de Otero-Pailos, autor que investiga 0 surgimento e o desenvolvimento da ideia de fenomenologia e como ela foi entendida no interior do discurso arquitetônico.

O debate em torno de uma revisão crítica do movimento Moderno, que passa ao período pluralista denominado Pós-Moderno (entendendo suas ambiguidades e generalidades), possui várias abordagens: políticas, éticas, linguísticas, estéticas e fenomenológicas (NESBITT, 2013 [1996]). Segundo Nesbitt, ao longo da história da Arquitetura, as questões foram tratadas tanto no campo conceitual quanto no físico: "As questões físicas são resolvidas à luz da tectônica, enquanto as questões conceituais ou intelectuais são problematizadas pela filosofia" (NESBITT, 2013 [1996], p. 15). Nesse contexto, a abordagem fenomenológica no campo da Arquitetura é parte deste conjunto complexo de revisão do movimento Moderno.

A aquisição mais importante da fenomenologia foi sem dúvida ter unido o extremo subjetivismo ao extremo objetivismo em sua noção do mundo ou da racionalidade. A racionalidade é exatamente proporcional às experiências nas quais ela se revela. [...] $\mathrm{O}$ mundo fenomenológico é não o ser puro, mas o sentido que transparece na intersecção de minhas experiências, e na intersecção de minhas experiências com aquelas do outro, pela engrenagem de umas nas outras; ele é portanto inseparável da subjetividade e da intersubjetividade que formam sua unidade pela retomada de minhas experiências 
passadas em minhas experiências presentes, da experiência do outro na minha (MERLEAU-PONTY, 2006 [1945], p. 18).

Por meio das abordagens de Norberg-Schulz, é possível exemplificar como a seara fenomenológica foi incorporada na Arquitetura, especificamente no que diz respeito ao lugar - discutindo suas questões físicas e metafísicas. Com o livro Genius loci: towards a phenomenology of Architecture (1979), Norberg-Schulz pretendeu conquistar uma dimensão existencial após décadas de teorias científicas - para o autor, o retorno ao entendimento das questões fenomenológicas e qualitativas da Arquitetura seria algo premente.

Isso porque a sociedade ocidental, historicamente, manteve a ideia de que a percepção deveria ser corrigida pela razão, que não era um elemento científico, considerada um auxiliar muito precário do conhecimento, algo que poderia depreciar seu entendimento - a verdade seria fruto de um pensamento racionalmente construído. A fenomenologia, ao associar sujeito e objeto, subjetividade e objetividade, defende que, mesmo o lado científico, advém de um conhecimento baseado na experiência do mundo - 0 corpo é a entidade da percepção, a principal referência espacial humana (MERLEAU-PONTY, 2006 [1945]).

O conteúdo poético da realidade, o a priori do mundo, que é o quadro fundamental de referência para qualquer arquitetura realmente significativa, fica escondido sob uma grande camada de explicações formais. Porque o pensamento positivista buscou a exclusão do mistério e da poesia, o homem contemporâneo vive com a ilusão do infinito poder da razão. Ele esqueceu sua fragilidade e sua capacidade de imaginar, geralmente assumindo que todos os fenômenos de seu mundo, da água ou fogo à percepção do comportamento humano, foram "explicados". Para muitos arquitetos, o mito e a poesia são geralmente considerados sinônimos de sonho e loucura, enquanto a realidade é considerada equivalente a prosaicas teorias científicas. [...] A arte pode ser bela, obviamente, mas apenas raramente ela é entendida como uma profunda forma de conhecimento, como uma forma genuína, intersubjetiva de interpretação da realidade (PÉREZ-GÓMEZ, 1983, p. 6, tradução nossa) ${ }^{1}$.

Diante da atual cultura globalizada, na qual o digital e o visual ganham protagonismo, Juhani Pallasmaa enfatiza a importância da experiência no mundo e na natureza da Arquitetura, investigando o papel dos sentidos em direção a uma Arquitetura multissensorial, detentora de um sentimento de integração entre o corpo e o espaço.

\section{INFLEXÃO HISTÓRICA: JORGE OTERO-PAILOS E A ARQUITETURA SOB O OLHAR FENOMENOLÓGICO}

Jorge Otero-Pailos é arquiteto, historiador e preservacionista espanhol radicado em Nova lorque. Em 1993, graduou-se em Arquitetura na Universidade de Cornell, tendo concluído o Mestrado nesta mesma instituição, em 1995, e concluído, no ano de 2002, o Doutorado (Ph.D.) em Arquitetura pelo Massachusetts Institute of Technology (MIT). Atualmente, Otero-Pailos é Diretor e Professor de Preservação Histórica na Universidade de Columbia (Nova Iorque).

Nas pesquisas referentes ao campo da história da Arquitetura, Otero-Pailos debruça-se sobre a história intelectual, procurando entender a formação das ideias e correntes de pensamento, tendo como horizonte as conexões sociais dos arquitetos. Em sua tese de Doutorado (2002), o autor investiga o surgimento e o desenvolvimento da ideia de fenomenologia no interior do discurso arquitetônico. Como resultado de pesquisas de Pós-Doutorado, o autor publica, em 2010, o livro Architecture's historical turn: phenomenology and the rise of the Postmodern, no qual busca clarificar a natureza da fenomenologia arquitetônica como uma das principais fontes intelectuais (ainda pouco estudadas) do pensamento arquitetônico pós-moderno (OTERO-PAILOS, 2010).

Deve-se destacar que o termo "fenomenologia arquitetônica" (architectural phenomenology, no original) é a expressão escolhida por Otero-Pailos para designar tanto o movimento intelectual, quanto o grupo de arquitetos que estabeleceram conexões entre a fenomenologia e a Arquitetura no período pós-Segunda Guerra. O termo será adotado no presente texto tendo como referência as discussões apresentadas no livro Architecture's historical turn.

Observa-se que o Pós-Modernismo na Arquitetura é mais facilmente reconhecido enquanto estilo do que como questão intelectual. As pesquisas de Otero-Pailos demonstram o papel da fenomenologia da Arquitetura na formação do pensamento Pós-Moderno - um papel que não é absoluto, mas que, ao mesmo tempo, não deveria ser negligenciado por aqueles que se debruçam sobre o estudo do Pós-Modernismo.

No centro das discussões de Otero-Pailos estão a questão da experiência corporal e o modo como esta é entendida e elaborada pelos arquitetos modernos e pós-modernos. O autor afirma que a experiência, para os modernos "clássicos", era pensada em termos de forma e espaço. Por outro lado, para os pós-modernos, 
a experiência era conceituada segundo as chaves de teoria e história. Na passagem de uma concepção para outra, a fenomenologia arquitetônica teve um papel primordial.

Subjacente a essa discussão está a afirmação do primado da experiência corporal direta no entendimento da Arquitetura. Em outros termos, trata-se da consideração de que a experiência das obras arquitetônicas em si é mais importante para o entendimento das mesmas do que qualquer discurso teórico sobre elas. Nesse contexto, a fenomenologia arquitetônica foi responsável pela reformulação dos paradigmas intelectuais da Arquitetura.

Naquilo que era considerado trabalho intelectual "legítimo" no campo arquitetônico, a teoria sempre teve um papel primordial. Em segundo lugar, aparecia aquilo que era considerado como simples representações e estetizações da teoria - como fotos, desenhos e diagramas. A mudança intelectual na Arquitetura no período pós-Segunda Guerra Mundial, como foi caracterizada por Otero-Pailos, pode ser observada quando se passou a analisar o conteúdo intelectual da Arquitetura em termos de códigos visuais e experienciais e isto passou a ser considerado um trabalho intelectual legítimo. Otero-Pailos identifica a figura do "arquitetohistoriador" como tendo um papel de destaque nesta mudança. A história da Arquitetura, até então, elaborada, majoritariamente, por historiadores da arte, passa a ser um campo disputado pelos arquitetos, tornando-se uma história feita por arquitetos e para (tendo em vista os) arquitetos.

A fenomenologia arquitetônica, segundo Otero-Pailos (2010), não foi um grupo auto-identificado, com um manifesto de formação - como a maioria dos grupos na história da Arquitetura. Antes, ela tomou forma e coerência nos círculos acadêmicos formados ao redor de alguns arquitetos: Ernesto Nathan Rogers (19091969), Jean Labatut (1899-1986), Charles Moore (1925-1993), Christian Norberg-Schulz (1926-2000) e Kenneth Frampton (1930-).

O fato de não ser um grupo auto-identificado e não se encaixar nos padrões historiográficos é uma das dificuldades para o estudo da fenomenologia arquitetônica, mas existem outras. Otero-Pailos destaca que há uma ideia amplamente difundida (mas equivocada) de que as mudanças intelectuais ocorram abruptamente. No caso do Pós-Modernismo, é como se este fosse uma ruptura brusca com o período anterior na história da Arquitetura. No entanto, o autor defende que as mudanças no pensamento não são súbitas - existem fases, existe um processo: a fenomenologia arquitetônica seria como uma fase inicial do Pós-Modernismo.

Neste ponto, apresenta-se uma segunda dificuldade: em relação ao Pós-Modernismo arquitetônico, são mais conhecidos e estudados o estruturalismo, o pós-estruturalismo e o desconstrutivismo (as fases mais "tardias" do Pós-Modernismo). Como relacionar essas fases com a fenomenologia arquitetônica? OteroPailos adverte sobre o risco que existe em "fisgar" algumas ideias do período pós-guerra, baseando-se apenas no fato de terem uma semelhança externa com ideias que sejam mais familiares, construindo, assim, uma espécie de arco contínuo ligando o passado ao presente. Outro equívoco é o de utilizar o entendimento presente para "editar" o passado, tentando combinar (forçadamente) as linhas divisórias do discurso arquitetônico contemporâneo com o passado (OTERO-PAILOS, 2010).

A partir deste cenário, seria correto afirmar que não existe um arco que ligue as ideias diretamente, do passado ao presente. Existem descontinuidades nos processos históricos - neste caso, entre as fases do Pós-Modernismo - e entre gerações de arquitetos. Otero-Pailos destaca os anos 1980 como o principal momento de debates sobre a fenomenologia arquitetônica entre duas gerações de arquitetos-historiadores: a primeira (adeptos da fenomenologia) formada no período pós-1945, composta por figuras como Charles Moore (1925-1993), Christian Norberg-Schulz (1926-2000) e Kenneth Frampton (1930-), e a segunda (adeptos de uma postura mais crítica em relação à fenomenologia) formada no período pós-1968, composta por Mark Jarzombek (1954-), Mark Wigley (1956-), Hilde Heynen (1959-) e Kenneth Michael Hays (1952-). Deve-se destacar que, nos anos 1980, o pós-modernismo declina enquanto "estilo" e irrompe enquanto discussão intelectual, segundo o levantamento de Otero-Pailos.

O conceito de arquiteto-historiador é fundamental para compreender tanto o trabalho de Otero-Pailos, quanto dos demais arquitetos estudados pelo autor. $\mathrm{O}$ arquiteto-historiador contrasta com as figuras do arquiteto moderno e do historiador da arte. Esta noção foi desenvolvida no texto Phenomenology and the Rise of the Architect-Historian, publicado em 2005. Nele, Otero-Pailos considera a importância dos embates entre gerações de arquitetos no desenvolvimento intelectual da Arquitetura:

Para neófitos como Charles Moore, Christian Norberg-Schulz, Kenneth Frampton, Robert Venturi, Joseph Rykwert, Dalibor Vesely, Juhani Pallasmaa e outros mais, seus mentores fizeram com que o Modernismo se perdesse, fazendo-o subserviente à economia de mercado, um fenômeno que eles pensavam ser particularmente grave nos Estados Unidos. Eles lançaram sua hostilidade contra a articulação fetichística da estrutura de Paul Rudolph, o funcionalismo corporativo de Gordon Bunshaft, contra a cumplicidade de Eero Saarinen 
com o grande negócio, e críticas semelhantes (OTERO-PAILOS, 2005, p. 2, tradução nossa) ${ }^{2}$.

Otero-Pailos observa que o perfil do arquiteto moderno surgiu como um modo de diferenciação dentro do campo da Arquitetura - este indivíduo não é apenas um arquiteto, é um "arquiteto moderno". Além disso, enquanto figura, o arquiteto moderno possuía vários atributos semelhantes ao do gênio-criador do período Romântico. As características principais do arquiteto moderno eram sua autonomia (ou seja, sua liberdade auto-guiada) e sua autoridade (isto é, o poder de comandar) sobre o campo da Arquitetura. Como consequência, o arquiteto moderno era capaz de determinar o que poderia considerado Arquitetura, distinto de uma simples "construção"

Além disso, ele determinava o que seria a Arquitetura que estava por vir, a Arquitetura do futuro (OTEROPAILOS, 2005). Esta argumentação pode ser comparada ao texto Eupalinos (1996 [1923]), de Paul Valéry (1871-1945), em que apresenta-se uma discussão sobre a classificação de edifícios que são "mudos", que "falam" e que "cantam". O que está em jogo na discussão da figura do arquiteto-historiador é a autoridade sobre o campo da Arquitetura. Quem pode decidir o que é Arquitetura e o que é apenas construção?

A figura do arquiteto moderno sofreu um grande abalo com a democratização e massificação do ensino de Arquitetura nos anos pós-Segunda Guerra ${ }^{4}$, atendendo a uma demanda por técnicos em lugar de gênioscriadores. A partir de então, o arquiteto moderno passa a ser um chefe dentro de uma equipe de tecnocratas (cf. OTERO-PAILOS, 2005). Isso provocou uma movimentação no interior das universidades estadunidenses, sobretudo nas escolas de elite, para preservar a figura do arquiteto moderno enquanto gênio-criador. É importante entender qual era o investimento dos estudantes dessas universidades para se tornarem arquitetos:

Estudantes em instituições de elite, que eram preparados para a posição de gênio-criador e que se privavam dos benefícios econômicos imediatos de seguirem a posição de arquitetos de mercado em troca das recompensas a longo prazo e do prestígio de tornar-se um arquiteto moderno, ficaram desiludidos ao descobrirem que seus investimentos tinham sido desvalorizados pelo aumento em números absolutos de arquitetos modernos (OTEROPAILOS, 2005, p. 4, tradução nossa) ${ }^{5}$.

Figuras como Jean Labatut e Ernesto Rogers trabalharam na disputa para preservar a genialidade do arquiteto moderno. Notadamente, seus alunos voltaram-se para as atividades de ensino, escrita e crítica da Arquitetura. Aos poucos, os mesmos perceberam que o status que almejavam poderia ser alcançado através do campo teórico na Arquitetura. Como não estavam envolvidos com a prática da Arquitetura, com o campo do projeto, estes arquitetos voltaram-se para a análise e a leitura das obras. Sobretudo a análise visual dos edifícios e lugares foi amplamente desenvolvida por arquitetos como C. Norberg-Schulz, transformando-se numa atividade intelectual genuína no campo da Arquitetura. Aparece então a ideia de "leitura criativa" das obras, sendo igualada ao processo de "projeto criativo". Os arquitetos historiadores não podiam dedicar-se à produção das construções, mas podiam fazer leituras "criativas" ${ }^{6}$ de obras de outros arquitetos.

Na disputa da autoridade sobre o campo arquitetônico, os arquitetos historiadores também passam a se contrapor aos historiadores da Arquitetura, produzindo obras polissêmicas e promovendo um discurso antiintelectual. De acordo com a análise de Otero-Pailos, a fenomenologia foi lida superficialmente e de modo estratégico pelos arquitetos historiadores, apenas para confirmar a nulidade do discurso (confrontando os historiadores) e o primado da criatividade (contrapondo-se aos arquitetos modernos). Além disso, com a leitura da fenomenologia era possível estabelecer um paralelismo entre a ideia de retorno às coisas e de retorno às raízes da Arquitetura moderna.

A ideia de retorno às origens garantiu o predomínio dos arquitetos historiadores sobre os arquitetos modernos e os (antigos) historiadores da Arquitetura. Tal estratégia consistia no apelo à lei básica da Arquitetura moderna, identificada por Otero-Pailos na rejeição de tudo o que limitasse a originalidade do gênio criador. Desse modo, só poderia ser considerado "moderno" quem estivesse livre de interferências, sejam elas vindas da academia ou de pressões da economia capitalista.

Assim, arquitetos historiadores como Norberg-Schulz e Moore zombaram dos arquitetos de mercado, minaram as convenções acadêmicas e prenderam os arquitetos modernos a inalcançáveis padrões de inflexível egomania. Quanto mais era exigido um retorno às fontes da arquitetura moderna, mais desesperadamente os arquitetos modernos, assombrados por seu flagrante desajuste, lutavam por serem consagrados pelos arquitetos historiadores. Assim os arquitetos modernos aos poucos transferiram sua autoridade aos arquitetos historiadores (OTERO-PAILOS, 2005, p. 7, tradução nossa) ${ }^{7}$.

Para o entendimento da fenomenologia arquitetônica, não é suficiente estruturar uma história das ideias e dos conceitos. Otero-Pailos ressalta que a disputa entre indivíduos e o embate entre gerações são 
instâncias que devem ser consideradas para que se tenha uma compreensão abrangente desse movimento intelectual. A figura do arquiteto-historiador é reveladora quanto a isto. Dentro dos estudos de Otero-Pailos o arquiteto norueguês Christian Norberg-Schulz é o epítome do arquiteto-historiador. Um dos pontos importantes são seus livros de análise formal; eles ofereceram uma alternativa válida ao projeto enquanto processo de criação. Os livros permitem uma leitura que é "criativa": Norberg-Schulz ajudou a consolidar e legitimar outros modos de se escrever a história da Arquitetura. As fotografias em seus livros não são apenas apêndices aos textos, mas constituem em si um discurso próprio.

Desse modo, a compreensão de Otero-Pailos sobre as relações entre fenomenologia e Arquitetura vão além da discussão sobre a validade dos conceitos da fenomenologia para a Arquitetura, lançando luz sobre tal movimento intelectual, que tende a passar despercebido (devido às dificuldades relativas a seu estudo: não se encaixa no esquema monográfico de pessoas/objetos - arquitetos/obras). Mas ao lançar luz, ajuda a entender questões atuais, como a profunda cisão entre teoria e prática no campo arquitetônico, e sobre as possibilidades sociais para os arquitetos (teoria e crítica).

\title{
3 FENÔMENO E LUGAR: A INFLUÊNCIA DE CHRISTIAN NORBERG-SCHULZ
}

O contato do indivíduo com o lugar se dá por meio da percepção, da experiência, vivência desse lugar. A Arquitetura é entendida, aqui, como gesto que constrói os lugares (a partir da tectônica), ou seja, interfere diretamente na experiência dos indivíduos no mundo, ao mesmo tempo em que, para se constituir, também se pauta por uma experiência do lugar vivida pelo arquiteto que o desenhará.

\begin{abstract}
Através das lentes da carreira intelectual de Norberg-Schulz, podemos começar a ver as mudanças que ocorreram na disciplina arquitetônica na década de 1970, enquanto o modernismo lutava com sua própria historicidade e pluralidade. A principal dessas transformações foi o surgimento do arquiteto-historiador, figura para a qual Norberg-Schulz desempenhou um grande papel para a formação. Estrategicamente, o arquiteto-historiador teve como objetivo tirar o controle da história da arquitetura dos historiadores da arte e, simultaneamente, tomar jurisdição sobre a estética arquitetônica dos projetistas (OTEROPAILOS, 2007, p. 238, tradução nossa) ${ }^{8}$.
\end{abstract}

As construções criam lugares por meio da reunião de espaços: a medida da obra é o próprio espaço, o próprio sítio. O espaço se torna lugar, o lugar se torna território, um território de alguém, constituindo seu mundo. Um projeto constrói um lugar, o qual representa a estrutura das relações sociais: em seu plano material, já que demarca uma região capaz de abarcar a vida humana; em seu plano simbólico, trazendo seu sentido social - a Arquitetura estabelece uma mediação poética entre o estranho e o familiar. Segundo Joseph Rykwert (2003 [1972]), ao sair do útero, o indivíduo adquire sua segunda pele, a Arquitetura, que o protege do mundo selvagem e incerto - da cabana primitiva às casas construídas sob os estilemas da razão e da técnica, chegando ao pluralismo pós-moderno.

Em um período de crise e revisão dos pressupostos modernos (pós-Segunda Guerra Mundial), o aporte fenomenológico é incorporado pela Arquitetura, iluminando-se a proposta de uma retomada das cidades por meio de um olhar atento às especificidades, que se debruça sobre o entendimento do sítio, da utilização do contexto como pretexto para a ação projetual: a História tem papel fundamental e questões projetuais são disparadas pelo locus da intervenção, entendido como um local prenhe de potencialidades, com características particulares, dobras e rugosidades.

Muito embora o arquiteto norueguês Christian Norberg-Schulz (1926-2000) seja creditado como o precursor ou fundador da abordagem fenomenológica no campo da Arquitetura e do Urbanismo, Otero-Pailos (2007) indica que, na realidade, a fenomenologia arquitetônica foi uma criação colaborativa nos anos 1970, não fundada por um indivíduo, especificamente. Para compreendê-la é preciso voltar-se para os círculos sociais e acadêmicos de Jean Labatut, Charles Moore, Kenneth Frampton (1930-, arquiteto anglo-americano), Dalibor Vesely (1934-2015, historiador e teórico da Arquitetura, de origem tcheca), Juhani Pallasmaa, entre outros. No entanto, David Seamon, defensor da fenomenologia arquitetônica nos Estados Unidos, se referiu a Norberg-Schulz como o pai fundador da abordagem fenomenológica na Arquitetura.

No livro "Phenomenologies of the city: studies in the history and philosophy of architecture" (2015), Henriette Steiner e Maximilian Sternberg indicam que houve uma primeira geração de fenomenólogos da Arquitetura, entre os quais podem ser mencionados quatro críticos, por suas contribuições significativas e amplamente lidas: Steen Eiler-Rasmussen (1898-1990, arquiteto e urbanista dinamarquês); Joseph Rykwert (1926-, historiador da arte britânico, de origem polonesa); Kenneth Frampton e Christian Norberg-Schulz.

Este último, responsável por estabelecer a relevância de filósofos como Heidegger para a Arquitetura e por reabrir a história como fonte de reflexão arquitetônica, cunhando a Fenomenologia do Lugar. A partir do 
entendimento da percepção como um meio de acesso ao mundo vivido e a fenomenologia como o estudo desse fenômeno ocorrido entre uma consciência e um objeto - independentemente de sua escala ou qualidade (MERLEAU-PONTY, 2006 [1945]), no autor Christian Norberg-Schulz, esse objeto é o lugar.

[Thorvald] Christian Norberg-Schulz (Oslo, 1926-2000) formou-se em Arquitetura no Instituto Federal de Tecnologia de Zurique (Eidgenossische Technische Hochschule - ETH, Zurique, Suíça) em 1949. Em 1964, concluiu seu Doutorado em Arquitetura no Instituto Norueguês de Tecnologia (Trondheim, Noruega), o qual desenhou seu primeiro livro, "Intentions in Architecture", publicado, originalmente, em 1963. Nele, defendeu, principalmente, que o meio influencia os seres humanos, sendo que o propósito da Arquitetura extrapola as definições dadas pelo funcionalismo, um dos grandes sustentáculos do Movimento Moderno.

$O$ arquiteto norueguês se formou justamente no período de revisão crítica do Movimento Moderno, sendo possível notar uma postura revisionista em suas proposições e estudos, da mesma forma ${ }^{9}$. A propósito, acredita que analisou a Arquitetura, em "Intentions in Architecture", de uma forma muito científica, muito analítica, deixando de lado as características do mundo concreto - Arquitetura analisada isoladamente, informação que o autor indica em seus dois livros seguintes relacionados à fenomenologia do lugar: "Existence, space and Architecture" (1971) e "Genius loci: towards a phenomenology of Architecture" (1979).

Os três livros formam uma sequência teórica alinhavada pela ideia central de que a Arquitetura representa um meio para dar ao indivíduo o que o autor chama de "ponto de apoio existencial". Para ele, o indivíduo não consegue um ponto de apoio em dimensões científicas, somente: são necessários símbolos, obras de arte que representem situações da vida. O papel destas obras de arte seria o de transmitir significados e, portanto, Norberg-Schulz se empenha em investigar as implicações psíquicas, metafísicas da Arquitetura, indo além de seu aspecto prático (embora admita que exista uma inter-relação entre os dois aspectos).

Para o autor, os arquitetos e urbanistas modernos, de modo geral, teriam deixado de lado a tão necessária dimensão existencial (com a proposta de tabula rasa, por exemplo), ainda que alguns tenham reconhecido a sua importância - "A dimensão existencial ('verdadeira') se manifesta na História, mas seus significados transcendem a situação histórica" (NORBERG-SCHULZ, 1980, p. 6, tradução nossa) ${ }^{10}$. Neste contexto, indica que é premente o retorno a um entendimento fenomenológico e qualitativo da Arquitetura, possibilitando a concretização do espaço existencial.

A conceituação de espaço existencial é feita no segundo livro, Existence, space and Architecture (1971): a noção de espaço existencial é oriunda da relação do corpo com o espaço - o espaço é um dos aspectos da orientação geral dos indivíduos e a forma de percebê-lo advém justamente de sua experiência de vida, de suas vivências, de sua interação com o ambiente no qual eles vivem. A partir disso, para Norberg-Schulz, a Arquitetura desenha espaços que vão além da geometria, isto é, considera também aspectos perceptivos e da paisagem, entre outros.

Após décadas de teorias científicas, percebe-se que o autor pretendia, com tal livro, a conquista de uma dimensão existencial no campo da Arquitetura e do Urbanismo, haja vista que, além disso, acreditava que ele próprio havia sido muito analítico em Intentions in Architecture - ao longo dos três livros mencionados, vai se corrigindo e trazendo novas perspectivas, aprofundamentos para questões anteriores, o que também se dá no que diz respeito aos métodos: o autor os aprimora focando, principalmente, na fenomenologia, tida, para ele, como um método, em que se retorna às coisas mesmas para entendê-las.

\begin{abstract}
Uma das principais contribuições historiográficas dessa abordagem foi redefinir as fontes primárias aceitáveis na escrita da história da arquitetura. Considerando que a história da arquitetura tradicional privilegiou os chamados documentos objetivos, como os esboços do arquiteto, a correspondência pessoal e a proveniência dos materiais de construção, a abordagem fenomenológica afirmou que os documentos subjetivos, como a experiência pessoal do historiador do edifício, também eram fontes primárias válidas (OTERO-PAILOS, 2007, p. 229, tradução nossa) ${ }^{11}$.
\end{abstract}

De Intentions in Architecture a Genius loci: towards a phenomenology of Architecture, Norberg-Schulz busca compreender, em suma, as relações básicas entre os indivíduos e o ambiente, mediadas pela Arquitetura. Tal abordagem se sustenta a partir de sua hipótese: o senso de um ponto de apoio à existência é oriundo da Arquitetura. Dito isso, as habitações seriam equivalentes ao ponto de apoio existencial e, sendo o propósito da Arquitetura promover o habitar, consequentemente, a Arquitetura seria a responsável por criar lugares que sejam pontos de apoio à existência humana ("existential foothold" = "dwelling", o propósito da Arquitetura). "O propósito existencial da construção (arquitetura) é, portanto, fazer com que um espaço se transforme em um lugar, ou seja, desvendar os significados potencialmente presentes no ambiente dado" (NORBERG-SCHULZ, 1980, p. 18, tradução nossa) ${ }^{12}$.

A natureza seria uma conjunção de elementos interrelacionados que expressam aspectos fundamentais da existência; assim, incorpora significados e oferece bases para o habitar - o projeto é um diálogo entre forma 
e contexto, bebe das fontes do lugar, entendido como a cristalização da história de seu percurso. Em Genius loci: towards a phenomenology of Architecture, o autor indica que um lugar é marcado por paisagens e assentamentos e pode ser entendido a partir do caráter e do desenho de seus espaços, sendo estes formados por uma componente estrutural (geometria tridimensional, materializada por meio de bordas e limites) e uma componente perceptiva (marcada por sua qualidade).

Não obstante, o autor destaca que é insatisfatório analisar o lugar somente em sua chave estrutural ou em sua chave perceptiva, pois não podem ser descritos de formas analíticas ou científicas, abstrações da realidade - isso deixaria escapar a experiência da vida cotidiana. O lugar é mais do que uma localização abstrata, é uma totalidade composta de elementos concretos, os quais têm substância, formato, textura, cor, um fenômeno qualitativo total que não pode ser reduzido a nenhuma das partes. Juntos, eles determinam o caráter e compõem uma atmosfera para o lugar.

Em linhas gerais, para o autor, um espaço é a organização tridimensional de elementos, com os quais se compõe um lugar, o qual é marcado por identidades particulares - os lugares seriam espaços (organizações tridimensionais de elementos) onde a vida ocorre, marcados por uma atmosfera correspondente a um caráter. Assim, os lugares podem ser descritos por substantivos (casa, bairro, cidade - o que são?); os espaços podem ser descritos por preposições, haja vista que são relações tridimensionais entre elementos (embaixo, atrás, antes, depois - onde estão?); já o caráter, por descrever um lugar por meio de sua atmosfera, pode ser indicado por meio de adjetivos (escuro, apertado, aconchegante - como são?).

Por isso mesmo, os lugares têm identidades particulares, descritas por questões qualitativas (componente perceptiva). Casas e cidades consistem em uma multiplicidade de lugares particulares. "Somente entendendo nosso lugar, poderemos participar de forma criativa e contribuir com sua história" (NORBERGSCHULZ, 1980, p. 202, tradução nossa) ${ }^{13}$. Diferentes ações demandam diferentes lugares, de diferentes caráteres: moradia (protetora); escritório (prático); salão de festas (festivo); igreja (solene).Todos os lugares têm caráter, ou seja, o modo como a vida é dada, sua constituição formal e material, sendo que somente a partir do entendimento do caráter do lugar é possível chegar ao seu genius loci, sua essência.

Genius loci é um conceito da Roma antiga, recuperado séculos depois por Norberg-Schulz: tal conceito aparece pela primeira vez no texto "Comentário à Eneida de Virgílio", de Servio, escritor romano: "nullus locus sine Genio" ("nenhum lugar é sem um Gênio"). Os seres independentes teriam um genius, um espírito guardião que dá vida às pessoas e aos lugares - do nascimento à morte, determinando seu caráter ou sua essência. Esse espírito guardião seria o responsável por guiar os indivíduos em suas decisões, inclusive orientando a escolha de um lugar para morar que os protegesse. Assim, constitui-se um liame entre terra e céu, entre homem e sagrado. Nesse sentido, indica o que algo é ou o que algo pretende ser (NORBERGSCHULZ, 1980). A Arquitetura seria a responsável por "liberar" essa essência ${ }^{14}$, compondo um lugar significativo e capaz de ser um ponto de apoio à existência humana, um habitar, sendo um elemento que proporciona ao indivíduo uma identificação consigo mesmo e, ao mesmo tempo, com o mundo; o lugar é parte integral da existência - "A identidade humana pressupõe a identidade do lugar" (NORBERG-SCHULZ, 1980 , p. 22, tradução nossa) $)^{15}$.

A paisagem reúne vários lugares, estabelece um laço entre indivíduo e meio, meio este que é composto por assentamentos de diversas escalas; assim, torna-se uma paisagem cultural, onde o indivíduo encontra significado como totalidade, carregando-a em seu corpo. As construções, ao repousarem sobre dado chão, interferem nessa paisagem, constroem um lugar, ao mesmo tempo em que sofre interferência dos mesmos, uma cumplicidade indissociável reforçada, ainda, pelas aberturas, que conectam o aqui e o além - habitar a casa é, a um só tempo, habitar o mundo. O espaço não é um continuum indiferenciado: antes de qualquer denominação técnica ou tipológica, o indivíduo prístino cravou uma pedra no chão, significou uma porção de terra, demarcou um espaço em meio a um mundo desconhecido, a partir dali, modificando-o. Retornar ao lugar é resgatar a origem da Arquitetura, quando uma pedra foi fincada no chão.

\section{ENSAIOS MULTISSENSORIAIS: O OLHAR FENOMENOLÓGICO DE JUHANI PALLASMAA NA ARQUITETURA}

Assim como Christian Norberg-Schulz, o arquiteto e teórico finlandês Juhani Pallasmaa trata do problema da perda de capacidade de comunicação da arquitetura. [...] Para o arquiteto, o significado depende da capacidade dos projetos de simbolizar a existência ou a presença humana e, como os arquitetos modernos parecem ter ignorado, da experiência espacial do trabalho. As formas em si não têm significado, mas podem comunicar um sentido por meio de imagens enriquecidas por associações (NESBITT, 2013 [1996], p. 481).

Juhani Pallasmaa, arquiteto e pensador reconhecido no meio acadêmico, procura destacar os conceitos da fenomenologia de Merleau-Ponty aplicados no campo da Arquitetura, elencando diversos arquitetos e 
exemplificando a questão da relação do corpo com a obra. O arquiteto percebe o espaço construído, seja pela Arquitetura, seja pela cidade. Mas o que significa perceber o espaço?

A "percepção" está associada à "sensação", porém, essa "sensação" vai além do "sentir": a "sensação" deve ser entendida pela maneira com a qual o sujeito é afetado e à própria experiência do estado deste sujeito. Na compreensão da "percepção" é preciso admitir que a "sensação" está aquém de qualquer "conteúdo qualificado". Acredita-se saber muito bem o que é "ver", "ouvir", "sentir" porque a "percepção" tem fornecido objetos coloridos e sonoros.

$\mathrm{Na}$ análise da "percepção", esses objetos são transportados para a consciência, o que os psicólogos chamam de experience error, ou seja, "[...] supomos de um só golpe em nossa consciência das coisas aquilo que sabemos estar nas coisas", (o que sabemos das coisas é o que se pode chamar de "qualidade" é uma propriedade do objeto). [...] Construímos a percepção com o percebido" (MERLEAU-PONTY, 2006 [1945], p. 26). Para Merleau-Ponty, essa percepção pelo percebido não pode ser a "qualidade" tomada como um elemento da consciência, como uma qualidade "muda", "plena" e "determinada".

A questão aponta para a substituição da experiência em si pelo uso dos registros de experiências anteriores, conduzindo a uma falta de distinção e compreensão das particularidades tanto das novas experiências quanto daquelas já passadas. A percepção não é a representação fiel do real. Ela se dá ao interagir com seu objeto, alterando-o. A percepção é alimentada pelas condições do lugar e do momento.

Pallasmaa percorre o mesmo caminho filosófico dos autores anteriormente citados, enaltecendo a questão dos sentidos na percepção do edifício e do lugar. Em seus textos, o autor faz referências à ausência dos sentidos nas obras arquitetônicas predominantemente funcionais com suas estruturas racionais, somando sua voz ao coro daqueles que criticam a Arquitetura de linhas retas, de formas geométricas, puras.

A arte da visão, sem dúvida, tem nos oferecido edificações imponentes e instigantes, mas ela não tem promovido a conexão humana ao mundo. O fato de o vocabulário modernista em geral não ter conseguido penetrar na superfície do gosto e dos valores populares parece ser resultado de sua ênfase visual e intelectual injusta; a arquitetura modernista em geral tem abrigado o intelecto e os olhos, mas tem deixado desabrigados nossos corpos e demais sentidos, bem como nossa memória, imaginação e sonhos (PALLASMAA, 2011 [1996], p. 19, grifo nosso).

Diante da estrutura do pensamento fenomenológico, Pallasmaa antecipa uma crítica específica à supremacia da visão quando diante de uma Arquitetura. No prefácio do livro Os Olhos da Pele, um desdobramento de Questions of Perception (1994), Steven Holl o descreve como uma discussão mais concisa e mais clara das dimensões fenomenológicas cruciais da experiência humana na Arquitetura. Ainda comenta que, desde a primeira década do século XXI, a sociedade tem vivido em um mundo de consumo, de publicidade, efêmero, que contribui para a redução da capacidade de reflexão do indivíduo; o mesmo ocorrendo na Arquitetura, onde as novas tecnologias digitais enaltecem a imagem midiática.

A ideia central do livro trata sobre a experiência de uma Arquitetura multissensorial; as características de espaço, matéria e escala são medidas igualmente pelos olhos, ouvidos, nariz, pele, língua, esqueleto e músculos. A Arquitetura reforça a experiência existencial, a sensação de pertencer ao mundo, e essa é essencialmente uma experiência de reforço de identidade pessoal. "Minha percepção é, portanto, não uma soma de pressupostos visuais, táteis e auditivos: eu percebo de maneira total com todo o meu ser: eu abarco uma estrutura única da coisa, um modo único de ser, o qual fala com todos meus sentidos ao mesmo tempo" (PALLASMAA, 2011 [1996], p. 20).

Nesse primeiro livro, dentre as três publicações aqui denominadas como uma trilogia - Os olhos da pele (2011 [1996]), As mãos inteligentes (2013) e A imagem corporificada (2013) - Pallasmaa questiona a dominância do sentido visual na cultura contemporânea, principalmente, na prática e educação arquitetônica atual. Descreve a predileção pelo senso da visão, que nunca foi tão evidente na Arte e na Arquitetura como nas últimas décadas, suprimindo os demais sentidos; na Arquitetura tem predominado um tipo de obra que busca imagens visuais surpreendentes e memoráveis. $O$ autor afirma que vem ocorrendo uma substituição das experiências plásticas e espaciais embasadas na existência humana: a Arquitetura tem adotado a estratégia psicológica da publicidade e da persuasão instantânea, "[...] as edificações se tornaram produtos visuais desconectados da profundidade existencial e da sinceridade" (PALLASMAA, 2011 [1996], p. 29).

Segundo o autor, houve uma mudança distinta na experiência sensorial e perceptual do mundo, a qual é refletida pela Arte e pela Arquitetura. Se se deseja que a Arquitetura tenha um papel emancipador ou curador, não basta apenas reforçar a erosão do significado existencial, deve-se refletir sobre a diversidade de meios secretos pelos quais a Arte e a Arquitetura estão vinculadas à realidade cultural e mental da nossa época. Questiona-se como a Arquitetura vem sendo ameaçada ou marginalizada pelas transformações 
políticas, culturais, econômicas, cognitivas e perceptuais da atualidade. "A arquitetura se tornou uma forma de arte ameaçada de extinção" (PALLASMAA, 2011 [1996], p. 33).

Pallasmaa afirma que as interpretações mais ricas provêm das formas arquetípicas mais simples: coluna, empena, arco, domo, torre. As críticas de que essa ênfase indicaria uma proposta estilística nostálgica (historicismo pós-moderno) são refutadas pela sensível e abstrata "arquitetura do silêncio" de Pallasmaa e sua objeção à colagem pós-moderna como um formalismo superficial (NESBITT, 2013 [1996], p. 482).

Segundo Pallasmaa (2011 [1996]), a Arquitetura que valoriza a vida deve atender a todos os sentidos simultaneamente e fundir a autoimagem do indivíduo com a sua experiência de mundo, tendo como tarefa mental fundamental a acomodação e a integração, articulando as experiências de estar no mundo e aumentando o senso de realidade e de si mesmo. A dimensão da escala arquitetônica e sua compreensão implicam a medição inconsciente do objeto ou do edifício com o corpo e a projeção do esquema corporal individual no espaço em questão. Ao invés de criar meros objetos de sedução visual, a Arquitetura relaciona, medeia e projeta significados.

A Arquitetura, quando significativa, faz experimentar aos indivíduos como seres humanos e espirituais. Para o autor este é de fato a fantástica função de todas as artes significativas. A recente supervalorização das dimensões intelectual e conceitual da Arquitetura contribuíram para o desaparecimento da sua essência física e sensual e este foco redutivo da Arquitetura amplifica o senso do que o autor denomina "autismo arquitetônico" (PALLASMAA, 2011 [1996], p. 39).

Em um sentido mais amplo, Pallasmaa (2017) afirma que além de serem exteriorizações e extensões das funções corporais humanas, os edifícios são projeções mentais, são a exteriorização da imaginação, da memória e das capacidades conceituais do ser humano. "As estruturas que o ser humano constrói 'domesticam' o mundo para que possamos habitá-lo e compreendê-lo. O mundo fora da casa é distinto daquele que seria confrontado sem o efeito mediador da casa" (PALLASMAA, 2017, p. 90).

Em "O fenômeno do lugar", Norberg-Schulz afirma que "morar numa casa é habitar o mundo". Essa concepção da casa como uma condensação de uma experiência mais geral do mundo influiu na importância que Pallasmaa atribui ao lugar da morada: 'Na verdade, uma casa é um instrumento metafísico, uma ferramenta mítica com a qual procuramos dar à nossa existência passageira um reflexo de eternidade (PALLASMAA, 2013, p. 481-2).

Assim como no texto "Os olhos da pele", em "Essências" (2018), Pallasmaa reitera que o sentido mais importante na experiência da Arquitetura não é a visão, mas o senso existencial do indivíduo, a Arquitetura é uma experiência do senso corporificado da existência e da identidade humana, do pertencimento ao mundo, sugerindo uma experiência corporificada para além dos cinco sentidos aristotélicos.

\section{CONCLUSÃO}

A Arquitetura discutida neste texto tem um alcance para além de si própria, ela faz a mediação entre o mundo externo e o mundo interno da identidade pessoal por meio da percepção, da ação iterativa e corporificada do indivíduo que vive e sente de modo experiencial essa Arquitetura que une objetividade e subjetividade, racionalidade e emoção, conhecimento e intuição, espaço e lugar. Pode-se afirmar que a aproximação da Arquitetura e do Urbanismo com estudos do campo da Filosofia - sobretudo no que diz respeito à fenomenologia - é um processo com mais de seis décadas e que, por conta disso, apresenta diferenças ao longo do tempo (deve-se notar que os autores apresentados têm publicações nas décadas de 1970, 1990 e 2010).

As pesquisas de Jorge Otero-Pailos tratam, sobretudo, da história intelectual da Arquitetura, tendo como horizonte as conexões sociais dos arquitetos. O autor defende que as interações entre a Arquitetura e a fenomenologia tiveram um papel importante na passagem do modernismo ao pós-modernismo. Além disso, no livro Architecture's historical turn: phenomenology and the rise of the Postmodern o autor procura deixar clara a natureza da fenomenologia arquitetônica como uma das principais fontes intelectuais do pensamento arquitetônico pós-moderno.

Christian Norberg-Schulz associa corpo, lugar e Arquitetura, partindo do entendimento de que o ambiente é a estrutura física e materializada da História, carregando em sua essência vestígios de seu percurso. Por meio do entendimento da essência do contexto (genius loci), a Arquitetura cria lugares, pontos de apoio à existência humana, uma segunda pele que protege o indivíduo do mundo selvagem e desconhecido, consoante uma abordagem fenomenológica diante do ambiente. Assim, defende que o conhecimento científico é fundado no mundo-da-vida, advém de uma experiência de mundo - neste caso, a experiência do 
lugar. O fenômeno do lugar é fundamental ao projeto de Arquitetura, entendido como uma amálgama entre obra e contexto.

Juhani Pallasmaa se detém ao sentido da Arquitetura e ao papel da percepção no projeto e na fruição das obras construídas. Para ele, a Arquitetura permite perceber e entender a dialética da permanência e da mudança, permite inserir o indivíduo no mundo e vivenciar um "continuum" da cultura e do tempo, é um instrumento de relação com o espaço e o tempo.

$\mathrm{Na}$ escrita dos três arquitetos, a experiência corporal é fundamental para o entendimento da Arquitetura. Isso é possível em razão das bases dadas pela fenomenologia. Este aporte não é um subjetivismo, é intelectualmente válido. Jorge Otero-Pailos, Christian Norberg-Schulz e Juhani Pallasmaa, embora tenham ênfases diferentes em seus estudos, partem de um solo comum: a importância da percepção como meio de acesso ao mundo, seu laço com a intelecção e sua característica fundante ao campo da Arquitetura e do Urbanismo. Os três pensadores, em graus distintos, indicam certa crítica à falta de humanismo da Arquitetura e das cidades modernas, com suas brancuras, racionalidades, funcionalidades e formas geométricas puras, que eclipsam a experiência sensorial e enevoam a linguagem tectônica do espaço edificado, distanciando o corpo de sua identidade com o ambiente.

Segundo os autores, a Arquitetura não pode ser entendida como um objeto externo à experiência e à consciência humanas, ela cria estruturas e horizontes para a percepção, assume um papel mediador para o entendimento do mundo.

\section{AGRADECIMENTOS}

O presente trabalho foi realizado com apoio da Coordenação de Aperfeiçoamento de Pessoal de Nível Superior - Brasil (CAPES) - Código de Financiamento 001.

As opiniões, hipóteses e conclusões ou recomendações expressas neste material são de responsabilidade do(s) autor(es) e não necessariamente refletem a visão da FAPESP. Processo no 2018/16973-1, Fundação de Amparo à Pesquisa do Estado de São Paulo (FAPESP).

\section{REFERÊNCIAS}

MERLEAU-PONTY, Maurice. Fenomenologia da percepção. $3^{\mathrm{a}}$ ed. São Paulo: Martins Fontes, 2006.

NESBITT, Kate (org.). Uma nova agenda para a Arquitetura: antologia teórica 1965-1995. São Paulo: Cosac Naify, 2013.

NORBERG-SCHULZ, Christian. Existence, space and architecture. London: Praeger Publishers, 1971.

. Genius loci: towards a phenomenology of architecture. New York: Rizzoli, 1980.

Intentions in Architecture. Cambridge: MIT Press, 1965.

OTERO-PAILOS, Jorge. Phenomenology and the Rise of the Architect-Historian. In: Repenser les limites: I'architecture à travers l'espace, le temps et les disciplines, 2005, Paris. Atas [...]. Paris: Publications de l'Institut national d'histoire de l'art, 2005. DOI: http://dx.doi.org/10.4000/books.inha.1449. Disponível em: http:// books.openedition.org/inha/1449. Acesso em: 6 out. 2020.

Photo[historio]graphy: Christian Norberg-Schulz's demotion of textual history. Journal of the Society of Architectural Historians, v. 66, n. 2, p. 220-241, jun/2007. DOI: 10.1525/jsah.2007.66.2.220. Disponível em: https://www.jstor.org/stable/10.1525/jsah.2007.66.2.220. Acesso em: 13 fev. 2020.

Architecture's historical turn. Phenomenology and the rise of the postmodern. Minneapolis: University of Minnesota Press, 2010.

Theorizing the Anti-Avant-Garde: Invocations of Phenomenology in Architectural Discourse, 1945-1989. 2002. Tese (Ph.D. em História e Teoria da Arquitetura) - Department of Architecture, Massachusetts Institute of Technology, Cambridge, 2002. Disponível em: https://dspace.mit.edu/handle/1721.1/8313\#files-area. Acesso em: 1 set. 2017.

PALLASMAA, Juhani. A Geometria do sentimento: um olhar sobre a fenomenologia da Arquitetura. In: Uma nova agenda para a Arquitetura: antologia teórica (1965-1995). [org. Kate Nesbitt; trad. Vera Pereira]. São Paulo: Cosac Naify, 2013, p. 481-489.

Habitar. São Paulo: Gustavo Gili, 2017.

Os olhos da pele: a Arquitetura e os sentidos. [trad. Alexandre Salvaterra]. Porto Alegre: Bookman, 2011.

Essências. São Paulo: Gustavo Gili, 2018. 
PÉREZ-GÓMEZ, Alberto. Architecture and the crisis of modern science. Cambridge: The MIT Press, 1983.

RYKWERT, Joseph. A casa de Adão no paraíso: a ideia da cabana primitiva na história da Arquitetura. São Paulo: Perspectiva, 2003.

STEINER, Henriette; STERNBERG, Maximilian. Phenomenologies of the city: studies in the history and philosophy of architecture. Farnham: England, 2015.

VALÉRY, Paul. Eupalinos ou O Arquiteto. [trad. Olga Reggiani]. Rio de Janeiro: Editora 34, 1996.

\section{NOTAS}

1 "The consequences of all this for architectural theory are enormous. The poetical content of reality, the a priori of the world, which is the ultimate frame of reference for any truly meaningful architecture, is hidden beneath a thick layer of formal explanations. Because positivistic thought has made it a point to exclude mystery and poetry, contemporary man lives with the illusion of the infinite power of reason. He has forgotten his fragility and his capacity for wonder, generally assuming that all the phenomena of his world, from water or fire to perception of human behavior, have been "explained." For many architects, myth and poetry are generally considered synonymous with dreams and lunacy, while reality is deemed equivalent to prosaic scientific theories. [...] Art can be beautiful, of course, but only seldom is it understood as a profound form of knowledge, as a genuine, intersubjective interpretation of reality. And architecture, particularly, must never partake of the alleged escapism of the other fine arts; it has to be, before anything else, a paradigm of efficient and economical construction" (PÉREZ-GÓMEZ, 1983, p. 6).

2 "To neophytes like Charles Moore, Christian Norberg-Schulz, Kenneth Frampton, Robert Venturi, Joseph Rykwert, Dalibor Vesley, Juhani Pallasmaa, and countless others, their elders had lead Modernism astray by making it subservient to the market economy, a phenomenon that they thought was particularly acute in America. They unleashed their hostility towards Paul Rudolph's fetishistic articulation of structure, towards Gordon Bunshaft's corporate functionalism, towards Eero Saarinen's complicity with big business, and the like" (OTERO-PAILOS, 2005, p. 2).

${ }^{3}$ Building, no texto original.

${ }^{4}$ É preciso lembrar que Otero-Pailos baseia-se nos contextos estadunidense e europeu, que contudo assemelham-se a processos ocorridos em outras regiões do mundo. No período entre 1947 e 1973 os cursos de graduação em Arquitetura nos EUA quase triplicaram, conforme dados apresentados pelo autor.

5 "Students at elite institutions, who were prepared for the position of genius-creator, and who denied themselves the immediate economic benefits of pursuing the position of commercial-architect in exchange for the long term rewards and prestige of becoming a modern-architect, were also disillusioned to find out that their investment had been devalued by the increase in sheer numbers of modern-architects" (OTERO-PAILOS, 2005, p. 4).

6 "Criativo" no sentido relativo ao "gênio-criador".

7 "Thus, architect-historians like Norberg-Schulz and Moore derided commercial-architects, undermined the conventions of academic scholarship, and held modern-architects to unattainable standards of uncompromising egomania. The stronger their demands for a return to the sources of modern architecture, the more desperately modern-architects, haunted by their exposed inadequacy, vied to be consecrated by architect-historians. Thus the modern-architect slowly yielded his authority to the architect-historian" (OTERO-PAILOS, 2005, p. 7).

8 "Through the lens of Norberg-Schulz's intellectual career, we can begin to view the changes that occurred in the architectural discipline in the 1970s as modernism grappled with its own historicity and plurality. Paramount among these transformations was the emergence of the architect-historian, a figure that Norberg-Schulz played a large role in shaping. Strategically, the architect-historian aimed to wrest control of architectural history from art historians and simultaneously seize jurisdiction over architectural aesthetics from designers" (OTERO-PAILOS, 2007, p. 238).

9 Em 1952, criou o PAGON (Grupo de Arquitetos Progressistas de Oslo, Noruega), para fornecer uma delegação norueguesa independente ao CIAM (junto a Arne Korsmo (1900-1968) e Sverre Fehn (1924-2009), entre outros).

10 "The existential dimension ('truth') becomes manifest in History, but its meanings transcend the historical situation" (NORBERGSCHULZ, 1980, p. 6).

11 "One of the main historiographical contributions of this approach was to redefine acceptable primary sources in writing the history of architecture. Whereas traditional architectural history privileged so-called objective documents such as the architect's sketches, personal correspondence, and the provenance of construction materials, the phenomenological approach asserted that subjective documents, such as the historian's personal experience of the building, were also valid primary sources" (OTERO-PAILOS, 2007, p. 229).

12 "The existential purpose of building (architecture) is therefore to make a site became a place, that is, to uncover the meanings potentially present in the given environment" (NORBERG-SCHULZ, 1980, p. 18).

13 "Only when understanding our place, we may be able to participate creatively and contribute to its history" (NORBERG-SCHULZ, 1980, p. 202).

${ }^{14}$ Diferentes arquitetos poderão interpretar tal essência de formas, evidentemente, diferentes, justamente por terem experiências de mundo também distintas: o que o fenômeno do lugar traz aos projetistas?

15 "Human identity presupposes the identity of place" (NORBERG-SCHULZ, 1980, p. 22).

NOTA DO EDITOR $\left(^{\star}\right)$ : O conteúdo do artigo e as imagens nele publicadas são de responsabilidade do(s) autor(es). 